\title{
Development and Characterization of Levodopa Loaded Pharmacosomes for Brain Targeting via Intranasal Route: Pharmacodynamic Evaluation in Rats
}

\author{
Yashaswini Kotha, Anil Goud Kandhula, Krishnaveni Janapareddi* \\ Department of Pharmaceutics, University College of Pharmaceutical Sciences, Kakatiya University, Warangal, Telangana, INDIA.
}

\begin{abstract}
Parkinson's is the second most common progressive neurodegenerative disease and affects $1-2 \%$ people over the age 50 . Levodopa is the drug of choice in the treatment of Parkinson's disease and exhibits low oral bioavailability $(30 \%)$ and very low brain uptake. In an attempt to improve brain uptake and to avoid degradation of levodopa in peripheral circulation, brain targeting of levodopa loaded pharmacosomes via nasal route has been investigated. Pharmacosomes are colloidal dispersions of drug covalently bound to lipids and may exist as ultrafine vesicular, micellar or hexagonal aggregates, depending on the chemical structure of the drug-lipid complex. Pharmacosomes loaded with levodopa were prepared by solvent evaporation method and the optimized formulation contained levodopa and egg lecithin in the ratio of 1:3. The mean globule size, PDI, zeta potential, drug content, entrapment efficiency and drug release of formulation (F5) were $123.2 \mathrm{~nm}, 0.211,-29.1 \mathrm{mV}, 96 \%, 99.97 \%$ and $62.1 \%$ respectively. Permeation enhancer, chitosan was incorporated at $0.5 \%$ concentration to optimal formulation (F7). The mean globule size, PDI, zeta potential, drug content, entrapment efficiency and drug release of optimised formulation (F7) were $125.5 \mathrm{~nm}, 0.115,+33.7 \mathrm{mV}, 96.5 \%, 99.98 \%$ and $91.2 \%$ respectively. Formation of covalent bond between levodopa and lecithin was confirmed by FTIR spectra showing peak at $1639.9 \mathrm{~cm}^{-1}$. Ex-vivo permeation studies using Franz diffusion cell on porcine nasal mucosa showed flux of 96.61 $\mu \mathrm{g} / \mathrm{cm}^{2} / \mathrm{h}$ and $302 \mu \mathrm{g} / \mathrm{cm}^{2} / \mathrm{h}$. The steady state flux of F5 and F7 formulations was significantly high $(P<0.001)$ and enhancement ratio was 2.26 and 3.12 times respectively compared to drug solution. Anti-parkinson's activity of
\end{abstract}

optimized formulation (F7), drug solution via nasal route was compared with drug solution administered orally, in rotenone induced male wistar rats. Group treated with optimized pharmacosomes formulation (F7) showed significant recovery in rat weight $(43 \%)$, locomotor activity by photo actometer $(90 \%)$ and grip strength on retard $(65 \%)$ compared to drug solution treated orally showed recovery in rat weight (32\%), locomotor activity by photo actometer $(57 \%)$ and grip strength on rotarod(30\%). Biochemical parameters measured in brain homogenate showed significant reduction in induced levels of nitric oxide $(82 \%)$, total protein $(88 \%)$ and lipid peroxides $(73 \%)$ and significant increase in reduced Glutathione $(67 \%)$. Whereas drug solution treated via orally showed significantly less activity in the reduction of nitric oxide $(28 \%)$, total protein $(59 \%)$ and lipid peroxidation $(33 \%)$ and reduced glutathione $(10 \%)$.

Key words: Brain targeting, Levodopa, Nasal delivery, Parkinson's disease, Pharmacosomes.

Correspondence

Dr. Janapareddi Krishnaveni,

Assistant Professor, Department of Pharmaceutics, Kakatiya University, Warangal-506009. Telangana, INDIA.

Phone: +919247161127

Email: krishnaveni.janapareddi@gmail.com

DOI: 10.5530/jyp.2020.12s.47

\section{INTRODUCTION}

Parkinson's is the second most common progressive neurodegenerative disease and affects $1-2 \%$ people over the age 50 . Levodopa is the drug of choice in the treatment of Parkinson's disease and exhibits low oral bioavailability (30\%) and very low brain uptake.Currently, so many drugs and conventional drug delivery methods have been developed for CNS diseases but they failed in showing the concentration required for action at targeted site i.e. brain due to BBB (Blood Brain Barrier) and BCB (Blood Cerebrospinal fluid Barrier). ${ }^{1,2}$ Two different approaches currently used to deliver therapeutics into the brain bypasses the $\mathrm{BBB}$ are: Invasive and Non-Invasive methods including BBB disruption, nasal delivery or colloidal drug carriers. ${ }^{3,4}$ Researches reported a direct transport of drugs from the nose to the brain via olfactory region. Uptake by the olfactory epithelium and transfer via the olfactory bulb into brain parenchyma; the nerve cells of the olfactory epithelium project into the olfactory bulb of the brain, which provides a direct connections between brain and the external environment. ${ }^{5-12}$

Pharmacosomes, bearing unique advantages over liposome and niosomes could serve as a potential alternative to conventional vesicles. These are colloidal dispersions of drug covalently bound to lipids and may exist as ultrafine vesicular, micellar or hexagonal aggregates, depending on the chemical structure of the drug-lipid complex..$^{13}$ As the system is formed by linking a drug (pharmakon) to a carrier (soma), they are termed as "Pharmacosomes". Pharmacosomes are prepared out of natural lipids, which are interesting candidates for brain targeting, due to rapid uptake by the brain, bioacceptability, biodegradability and less toxicity compared to the polymeric nanoparticles. Any drug possessing an active hydrogen atom $\left(-\mathrm{COOH},-\mathrm{OH},-\mathrm{NH}^{2}\right.$, etc.) can be esterified to the lipid, with or without spacer chain that strongly result in an amphiphilic compound, which will facilitate membrane, tissue, or biological cell wall. ${ }^{14,15}$

Chitosan has been investigated for particulate delivery to brain for various drugs. Chitosan is a linear polysaccharide which is derived from naturally occurring chitin by deactivation with exposed amino group responsible for rendering the polymer cationic. This property in addition to its mucoadhesive nature and its influence on the permeability of epithelial membranes. ${ }^{16-19}$

In an attempt to improve brain uptake and to avoid degradation of levodopa in peripheral circulation, brain targeting of levodopa loaded pharmacosomes via nasal route has been investigated. The prepared

This is an open access article distributed under the terms of the Creative Commons Attribution-NonCommercial-ShareAlike 4.0 License, which allows others to remix, tweak, and build upon the work non-commercially, as long as the author is credited and the new creations are licensed under the identical terms. 
pharmacosomes were optimized for formulation parameters to obtain desired mean globule size, PDI, zeta potential, drug content, entrapment efficiency and drug release. Ex-vivo permeation studies using Franz diffusion cell on porcine nasal mucosa PBS buffer $\mathrm{pH} 6.4$ were carried out. In vivo studies in rat model were carried out to account for the recovery of the drug in brain following intranasal administration of optimized formulation (F7), drug solution via nasal route was compared with drug solution administered orally, in rotenone induced male wistar rats. The results were determined and compared with the plain drug solution.

\section{Materials}

Levodopa was a gift sample from glochem private limited, egg lechitin (Tokyo chemical industry, Japan), tetrahydrofuran and low molecular weight chitosan were purchased from sigma Aldrich. Water used was ultrapure grade Millipore. All other reagents were of analytical reagent grade.

\section{Animals}

Male Wistar rats, weighing between 300 and $350 \mathrm{~g}$ were obtained from Sainadh Agencies, Hyderabad, India, after getting approval from "Committee for the Purpose of Control and Supervision of Experiments on Animals" (CPCSEA) and Institutional Animal Ethics Committee (IAEC), Kakatiya University (KU). The approval number IAEC/31/ $\mathrm{UCPS} / \mathrm{KU} / 2019$. Animals were provided standard laboratory diet, water ad libitum and acclimatized to laboratory conditions $\left(22 \pm 2^{\circ} \mathrm{C}, 12-\mathrm{h}\right.$ light-dark cycle and 55-65\% humidity) 1 week prior to initiation of experiments.

\section{MATERIALS AND METHODS}

\section{Drug characterization by FT-IR}

Pure drug, phospholipid and optimised formulation were analysed by FTIR (Bruker FT-IR Tensor 27) spectroscopy with $\mathrm{KBr}$ disc method. The spectrum was obtained at a resolution of $4 \mathrm{~cm}^{-1}$ between frequency range of $4000-400 \mathrm{~cm}^{-1}$.

\section{Estimation by HPLC}

The HPLC equiped with Pump, LC 20-AD Prominence; Detector, UV-Visible SPD-20A Prominence was used for the estimation. The column used was Reverse Phase $\mathrm{C}_{18}$ column, Phenomenix $(250 \times 4.6 \mathrm{~mm}$, $5 \mu \mathrm{m}$ size). The mobile phase was composed of methanol, $0.5 \%$ acetic acid in the ratio of 70:30 v/v. The injection volume was $20 \mu \mathrm{L}$. The detection wave length was $284 \mathrm{~nm} .^{20}$

Different dilutions were made with mobile phase to obtain $0.1,0.25,0.5$, $0.75,1,2,3,4,5 \mu \mathrm{g} / \mathrm{ml}$ with mobile phase. The solutions were injected into HPLC column. The standard graph was plotted based on peak area from the obtained chromatogram on Y-axis and Drug concentration on $\mathrm{X}$-axis. (Peak area Vs concentration).

\section{Preparation of pharmacosomes}

Pharmacosomes were prepared by solvent evaporation method. Accurately weighed amounts of drug and lipids were dissolved in volatile organic solvent such as tetrahydrofuran in a round bottom flask. The organic solvent was evaporated at room temperature using a rotary flash evaporator which leaves a thin film of solid mixture deposited on walls of flask. The dried film was then hydrated with distilled water to form vesicles (pharmacosomes) embedded with levodopa. ${ }^{21}$ The composition of various pharmacosomes of Levodopa was given in Table 1.

\begin{tabular}{|cccccc}
\hline \multicolumn{6}{|c|}{ Table 1: Composition of various pharmacosomes of levodopa. } \\
\hline Formulations & $\begin{array}{c}\text { Drug } \\
(\mathbf{m g})\end{array}$ & $\begin{array}{c}\text { Egg } \\
\text { Lecithin } \\
(\mathrm{mg})\end{array}$ & $\begin{array}{c}\text { Tetrahydrofuran } \\
(\mathrm{ml})\end{array}$ & $\begin{array}{c}\text { Water } \\
(\mathrm{ml})\end{array}$ & $\begin{array}{c}\text { Chitosan } \\
(\%)\end{array}$ \\
\hline F1 & 75 & 75 & 5 & 5 & - \\
F2 & 75 & 112.5 & 5 & 5 & - \\
F3 & 75 & 150 & 5 & 5 & - \\
F4 & 75 & 187.5 & 5 & 5 & - \\
F5 & 75 & 225 & 5 & 5 & - \\
F6 & 75 & 225 & 5 & 5 & 0.25 \\
F7 & 75 & 225 & 5 & 5 & 0.50 \\
F8 & 75 & 225 & 5 & 5 & 0.75 \\
F9 & 75 & 187.5 & 5 & 5 & 0.50 \\
\hline
\end{tabular}

\section{Characterization of pharmacosomes Mean globule size, poly dispersity index (PDI) and zeta potential}

The mean globule size analysis, PDI and zeta potential of formulation were determined using Zeta sizer (Nano-ZS 90, Malvern instruments Ltd.UK) on 100 times diluted sample. ${ }^{22,23}$

\section{Drug content}

Accurately weighed amount of pharmacosomes were suitably diluted with methanol, sonicated, filtered through $0.45 \mu \mathrm{m}$ filter and analyzed using UV-Visible spectroscopy. ${ }^{23}$

\section{Determination of entrapment efficiency}

The free drug in the aqueous phase was determined by separation by ultra-filtration using centrisort tubes. The amount of levodopa in the aqueous phase was estimated by HPLC method.

Entrapment efficiency $=$ Total drug - Free drug/ Total drug ${ }^{\star} 100$

\section{In vitro drug release study of pharmacosomes}

In vitro drug release studies were assessed using Franz diffusion cell. Pharmacosomes formulation equivalent to $15 \mathrm{mg}$ of levodopa was placed in donor compartment separated from receptor compartment with dialysis membrane of molecular weight cutoff 1200-14000 daltons. Aliquots of samples were withdrawn from the receptor compartment at predetermined time intervals and replaced with fresh medium. The samples were then analyzed for drug content by UV-Visible Spectrophotometer at $280 \mathrm{~nm}$.

\section{Ex vivo permeation studies}

Ex vivo permeation studies were performed on porcine nasalmucosa using Franz diffusion cells. The isolated porcine nasal mucosa was mounted on franz diffusion cells and allowed to equilibrate for $30 \mathrm{~min}$ in PBS pH 6.4 at room temperature. After equilibration the donor chamber was replaced with formulation/drug solution and the receptor was filled with fresh medium. ${ }^{24,25}$ Samples were withdrawn at regular intervals up to $8 \mathrm{hrs}$. And replaced with fresh medium. The samples were analyzed by UV Visible spectrophotometer at $280 \mathrm{~nm}$. The cumulative amount of drug permeated at different time points was calculated using the following formula 


$$
\mathrm{Q}=\left[\mathrm{C}_{\mathrm{n}} \mathrm{V}+\sum_{\mathrm{i}=1}^{\mathrm{n}-1} \mathrm{C}_{\mathrm{i}} \mathrm{S}\right]
$$

Where, $\mathbf{Q}=$ Cumulative amount of drug released; $\mathbf{C}_{\mathbf{n}}=$ Concentration of $\operatorname{drug}(\mu \mathrm{g} / \mathrm{mL})$ determined at $\mathrm{n}^{\text {th }}$ sampling interval; $\mathbf{V}=$ Volume of receptor compartment; $\mathrm{n}-1 \Sigma \mathrm{C}_{\mathrm{i}} \mathrm{S} \mathrm{i}=1=$ Sum of concentration $(\mu \mathrm{g} / \mathrm{ml})$ determined at sampling points 1 to $\mathrm{n}-1$ multiplied with sampling volume (S).

\section{Determination of steady state flux $\left(\mathrm{J}_{s s}\right)$, Permeability coefficient (Kp), Enhancement ratio (ER)}

The cumulative amount of levodopa permeated through excised porcine nasal mucosa was plotted as a function of time. Steady state flux $\left(\mu \mathrm{g} / \mathrm{cm}^{2} / \mathrm{h}\right)$ was calculated from the linear portion of the plot by regression. The flux at steady-state was calculated as the slope divided by the effective nasal mucosa surface area $\left(\mathrm{cm}^{2}\right)$. Permeability coefficient $\left(K_{\mathrm{p}}, \mathrm{cm} / \mathrm{h}\right)$ was calculated by dividing flux $\left(J_{\text {ss }} / \mathrm{Cd}\right)$ initial concentration of the drug in the donor cell. Enhancement ratio (ER) was calculated by dividing $J_{\mathrm{ss}}$ of the respective formulation by $J_{\mathrm{ss}}$ of the drug solution.

\section{Nasal cilio toxicity studies}

Nasal mucosa mounted on Franz diffusion cell was treated for 1h with formulation, Drug solution, isopropyl alcohol (positive control) and PBS pH 6.4 (negative control). The mucosa after treatment were rinsed with PBS pH 6.4 and preserved in 10\% v/v formalin solution. The mucosal section obtained by microtome technique was stained with hematoxylineosin and observed under digital microscope to evaluate the damage to nasal mucosa. ${ }^{26,27}$

\section{Scanning electron microscopy (SEM)}

The morphology of optimized pharmacosomes was studied by scanning electron microscope (JSM-6510LA, JEOL and Indonesia). The sample was adhered on to the carbon-coated metallic stub, sputter coated with platinum coating machine (JFC-1600 Auto fine coater, JEOL). Image was carried out under high vaccum. ${ }^{27}$

\section{Stability studies}

Stability studies were conducted for optimized formulation at room temperature and refrigerator conditions for two months. Samples were withdrawn at monthly intervals and analyzed for mean globule size, PDI and Zeta potential.

\section{In vivo studies}

Male Wistar rats were weighed and randomly divided into five groups, each group consisting of six rats weighing between 300 and 350 g. Group -I: Normal Saline $(0.9 \% \mathrm{w} / \mathrm{v}$ of $\mathrm{NaCl})$ Intraperitonially (IP) $(10 \mathrm{ml} / \mathrm{kg})$.Group II: Positive control -Rotenone - Intraperitonially $(3 \mathrm{mg} / \mathrm{kg})$. Group III: Rotenone (3mg/kg, 1-11days) + drug solution (oral, $8.8 \mathrm{mg} /$ $\mathrm{kg}, 12-21$ days). Group IV: Rotenone (3mg/kg, 1-11days) +drug solution (i.n, $2.5 \mathrm{mg} / \mathrm{kg}, 12-21$ days). Group V: Rotenone (3mg/kg, 1-11days) + optimized Pharmacosome formulation F7 (i.n, $1.25 \mathrm{mg} / \mathrm{kg}, 12-21$ days).

The behavioural parameters were recorded on $1^{\text {st }}, 12^{\text {th }}, 15^{\text {th }}, 18^{\text {th }}$ and $21^{\text {st }}$ day. To assessed the anti-Parkinson activities of test formulations. PD induction and progression were assessed by recording changes in weight, locomotor activity by photoactometer and grip strength by rota rod test. Standard calibration curve of levodopa was prepared in rat brain homogenate was calculated. Rats were sacrificed on $22^{\text {nd }}$ day by cervical dislocation method and brains were isolated. Brain samples were homogenized and immediately centrifuged (10 $000 \mathrm{rpm})$ for $10 \mathrm{~min}$ at ambient temperature. After centrifugation, supernatant plasma was transferred into clean, fresh Eppendorf's tube and stored in freezer at
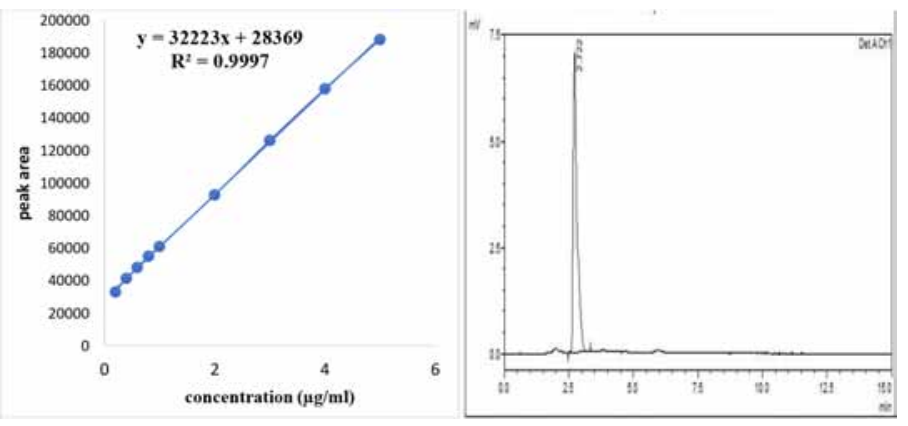

Figure 1: Chromatogram of levodopa showing retention time peak at $2.72 \mathrm{~min}$.

Table 2: Mean globule size, PDI, Zeta Potential, Drug content and Entrapment efficiency of various formulations.

\begin{tabular}{|c|c|c|c|c|c|}
\hline 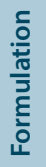 & 疍 & $\bar{a}$ & 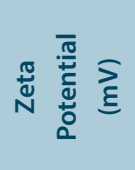 & 온 & 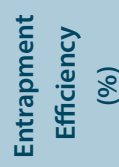 \\
\hline F1 & $237.5 \pm 2.7$ & $0.46 \pm 0.05$ & $-18.6 \pm 1.5$ & 97.2 & 99.95 \\
\hline $\mathrm{F} 2$ & $216.2 \pm 4.3$ & $0.340 \pm 0.11$ & $-22.7 \pm 0.2$ & 98.8 & 98.97 \\
\hline F3 & $199.8 \pm 2.8$ & $0.334 \pm 0.10$ & $-28.4 \pm 1.3$ & 95.6 & 98.95 \\
\hline $\mathrm{F} 4$ & $145.1 \pm 3.6$ & $0.259 \pm 0.13$ & $-27.1 \pm 0.2$ & 96.8 & 99.93 \\
\hline F5 & $123.2 \pm 2.9$ & $0.211 \pm 0.06$ & $-29.1 \pm 0.8$ & 97.0 & 99.97 \\
\hline F6 & $128.6 \pm 4.3$ & $0.297 \pm 0.07$ & $+28.6 \pm 0.6$ & 96.8 & 99.98 \\
\hline F7 & $125.5 \pm 5.2$ & $0.115 \pm 0.15$ & $+33.7 \pm 0.5$ & 97.5 & 99.98 \\
\hline F8 & $126.3 \pm 2.7$ & $0.124 \pm 0.06$ & $+34.5 \pm 1.3$ & 96.3 & 99.97 \\
\hline F9 & $140 \pm 1.9$ & $0.212 \pm 0.11$ & $+31 \pm 0.9$ & 96.1 & 99.95 \\
\hline
\end{tabular}

Each value represents the mean $\pm \mathrm{SD}(n=3)$.

$-20^{\circ} \mathrm{C}$ to estimate biochemical parameters such as reduced glutathione (GSH), lipid peroxidation, nitric acid level and total protein..$^{28-32}$

\section{RESULTS AND DISCUSSION}

\section{Standard graphs of levodopa by HPLC}

Dilutions were made as per procedure mentioned above and the chromatogram of levodopa was shown in Figure 1.

\section{Characterization}

All the formulations were characterized for mean globule size, poly disparity index and zeta potential, drug content, entrapment efficiency and drug release and results were shown in the Table 2 . The mean globule size of formulations was in the range of $123 \mathrm{~nm}$ to $237 \mathrm{~nm}$. The PDI of formulations was in the range of 0.1-0.4 indicating uniform dispersion of globules. Formulations F1 to F5 showed negative zeta potential values ranging -18 to $-29 \mathrm{mv}$. The zeta potential values of mucoadhesive pharmacosomes F6, F7, F8 and F9 were positive and in the range of +28.6 to $+33.5 \mathrm{mV}$ due to the presence of chitosan, a cationic polymer, which imparts positive charge to the globules. The drug entrapment efficiency of all formulations was above 98\%. The drug content of different formulations was found to be in the range of $98.92 \%$ to $99.99 \%$. In vitro drug release was $63.37 \%$.

\section{In-vitro drug release studies}

The drug release was measured over a period of $8 \mathrm{hrs}$ in phosphate buffer $\mathrm{pH} 6.4$ by Franz-diffusion cell method. The release profiles shown 


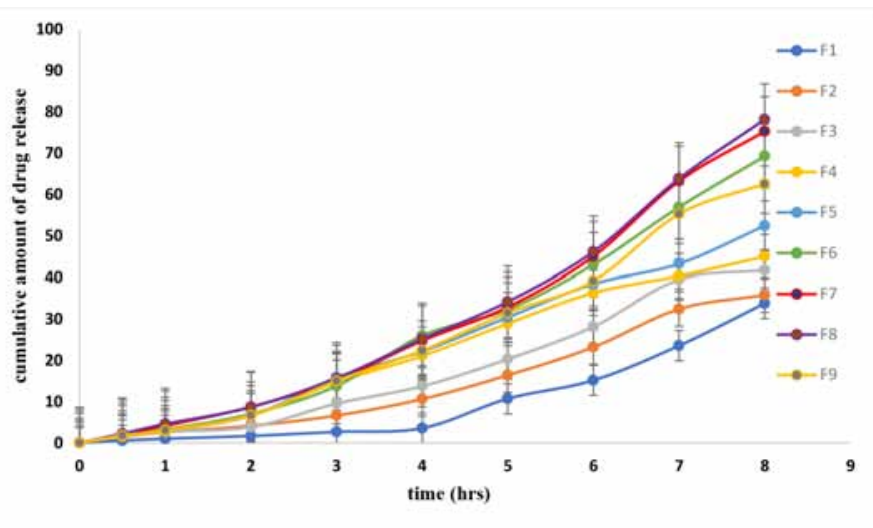

Figure 2: In vitro drug release profiles of pharmacosomes.

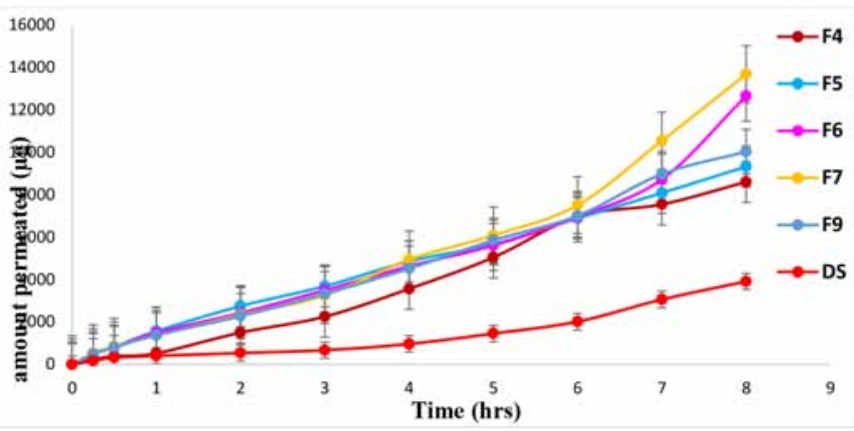

Figure 3: Amount of drug permeated $(\mu \mathrm{g})$ from pharmacosomal formulations and drug solution.

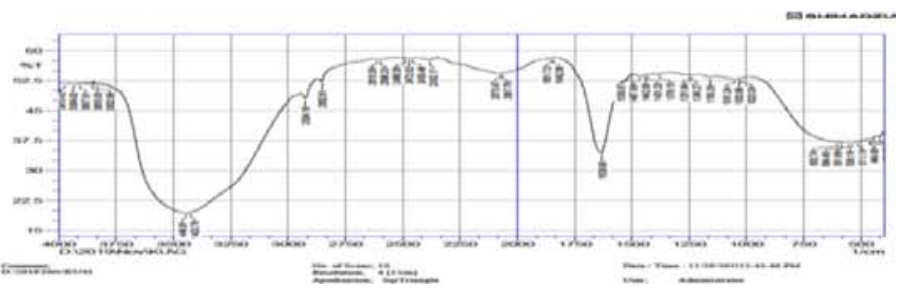

Figure 4: FT-IR of optimized formulation F7.

in Figure 2. The in-vitro drug release showed higher drug release from F7 formulation in 8 hrs $(75.30 \%)$.

\section{Ex vivo permeation studies}

The ex-vivo permeation profiles of selected formulations and drug solution were shown in Figure 3 and flux values in Table 3. Flux value at steady state was observed between 199.26 to $302.13 \mu \mathrm{g} / \mathrm{cm}^{2} /$ hr. Formulation containing chitosan at $0.5 \% w / w$ concentration (F7) showed maximum flux $302.13 \mu \mathrm{g} / \mathrm{cm}^{2} / \mathrm{hr}$ of which was significantly high compared to drug solution $96.61 \pm 1.49 \mu \mathrm{g} / \mathrm{cm}^{2} / \mathrm{hr}$. The enhancement ratio of F7 was 3.12 times when compared to drug solution and 2.26 times compared to F5 formulation.

\section{FTIR Spectra of optimized formulation F7}

FTIR spectra of optimized formulation F7 showing a peak at $1639.9 \mathrm{~cm}^{-1}$ indicating $\mathrm{C}=\mathrm{N}$ bond as shown in Figure 4. A covalent bond between levodopa and lecithin of pharmacosomes. Amine group of levodopa reacts with carbonyl groups of lecithin at $\mathrm{C}_{18}$ and $\mathrm{C} 23$ to give imine
Table 3: Steady state Flux, $K_{p}$ ER values of selected formulations and drug solution.

\begin{tabular}{ccccc}
\hline S.no & $\begin{array}{c}\text { Formulation } \\
\text { Code }\end{array}$ & $\begin{array}{c}\text { Flux } \\
\left(\mu \mathrm{g} / \mathrm{cm}^{2} / \mathrm{h}\right) \\
\mathrm{Jss}\end{array}$ & $\begin{array}{c}\mathrm{Kp} \times 10-3 \\
(\mathrm{~cm} / \mathrm{h})\end{array}$ & $\begin{array}{c}\text { Enhancement } \\
\text { Ratio }\end{array}$ \\
\hline 1. & F4 & $199.26 \pm 1.23$ & 13.16 & 2.06 \\
2. & F5 & $239.15 \pm 1.05$ & 14.61 & 2.26 \\
3. & F6 & $270.38 \pm 0.78$ & 18 & 2.79 \\
4. & F7 & $302.13 \pm 2.01$ & 20.1 & 3.12 \\
5. & F9 & $255.57 \pm 1.57$ & 15.03 & 2.64 \\
6. & DS & $96.61 \pm 1.49$ & 6.44 & 1 \\
\hline
\end{tabular}

Each value represents the mean $\pm \mathrm{SD}(n=3)$

Table 4: Effect of storage conditions on optimized pharmacosome formulation F7.

\begin{tabular}{|c|c|c|c|c|}
\hline Day & Conditions & $\begin{array}{c}\text { Mean } \\
\text { globule } \\
\text { size }(\mathrm{nm})\end{array}$ & PDI & $\begin{array}{c}\text { Zeta } \\
\text { potential } \\
(\mathrm{mV})\end{array}$ \\
\hline \multirow[t]{2}{*}{1} & $\begin{array}{c}\text { Room temperature } \\
\left(25^{\circ} \mathrm{C}\right)\end{array}$ & $125.5 \pm 5.2$ & $0.115 \pm 0.15$ & $+33.7 \pm 0.5$ \\
\hline & $\begin{array}{c}\text { Refrigerated } \\
\text { temperature }\left(4^{\circ} \mathrm{C}\right)\end{array}$ & $125.5 \pm 5.2$ & $0.115 \pm 0.15$ & $+33.7 \pm 0.5$ \\
\hline \multirow[t]{2}{*}{30} & $\begin{array}{c}\text { Room temperature } \\
\left(25^{\circ} \mathrm{C}\right)\end{array}$ & $128 \pm 5.8$ & $0.148 \pm 0.27$ & $+33.4 \pm 0.84$ \\
\hline & $\begin{array}{c}\text { Refrigerated } \\
\text { temperature }\left(4^{\circ} \mathrm{C}\right)\end{array}$ & $127 \pm 4.4$ & $0.120 \pm 0.21$ & $+33.5 \pm 0.73$ \\
\hline \multirow[t]{2}{*}{60} & $\begin{array}{c}\text { Room temperature } \\
\left(25^{\circ} \mathrm{C}\right)\end{array}$ & $133 \pm 4.8$ & $0.26 \pm 0.37$ & $+32.9 \pm 0.92$ \\
\hline & $\begin{array}{c}\text { Refrigerated } \\
\text { temperature }\left(4^{\circ} \mathrm{C}\right)\end{array}$ & $129 \pm 3.7$ & $0.21 \pm 0.23$ & $+33.1 \pm 0.48$ \\
\hline
\end{tabular}

Each value represents the mean $\pm \mathrm{SD}(n=3)$

$(\mathrm{C}=\mathrm{N})$. Formation of the imine functional group was confirmed by FTIR spectra.

\section{Scanning Electron Microscopy (SEM)}

Optimized formulation was subjected to SEM to study surface morphology. The SEM image of F7 formulation as shown in Figure 5 contained spherical shaped globules in group.

\section{Stability studies}

Optimized formulations was subjected for stability studies, stored at room temperature $\left(25^{\circ} \mathrm{C}\right)$ and refrigerated temperature $\left(4^{\circ} \mathrm{C}\right)$ for 2 months and results were Table 4 . There was no significant difference observed in mean globule size and zeta potential but slight increase in PDI was observed.

\section{Nasal toxicity studies}

Nasal toxicity studies were conducted and the images of the mucosa stained with eosin and hematoxylin were shown in Figure 6. From the observations of the images, one can conclude that F7 and drug solution were safe without any significant toxicity. The mucosa treated with isopropyl alcohol (positive control) showed complete disruption of epithelial layer and damage of tissue. 


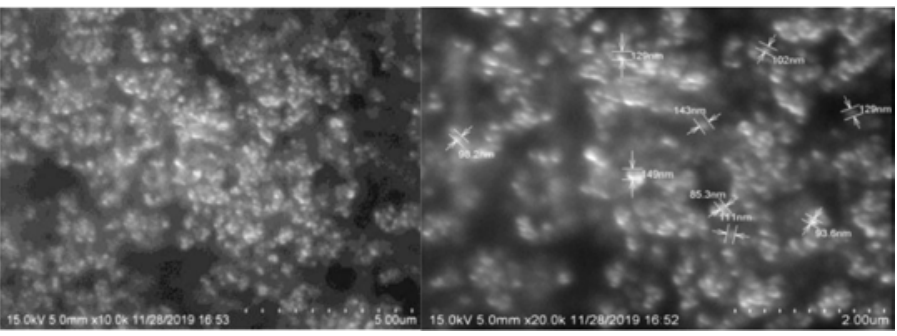

Figure 5: SEM image of optimized formulation F7 (5.0mm x 20.0k magnification).

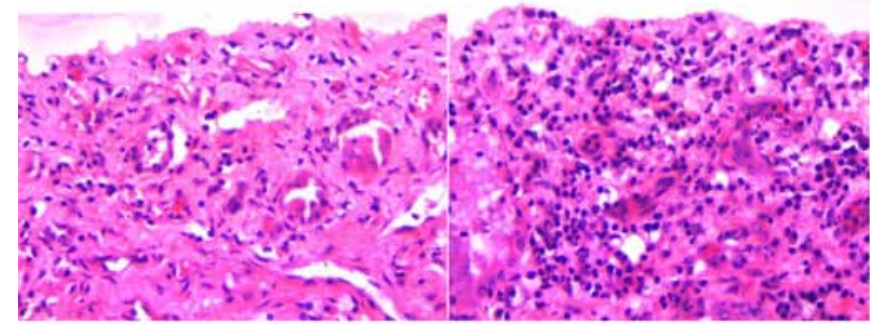

(a) pH 6.4 PBS

(b) isopropyl alcohol

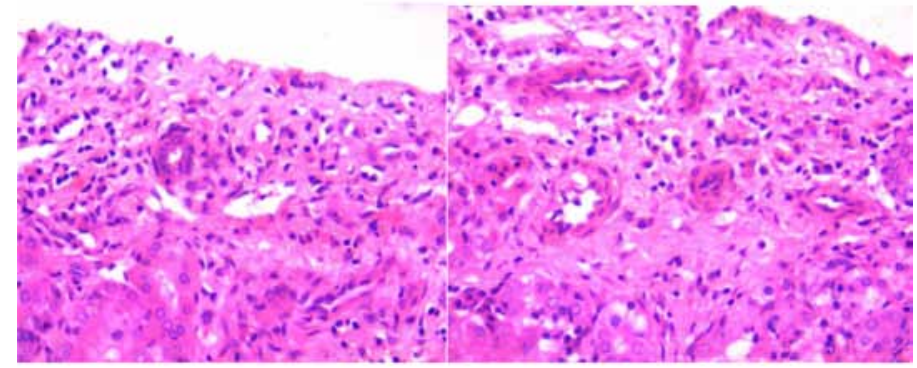

(c) drug solution

(d) optimized pharmacosomes F7

Figure 6: Histopathology images of porcine nasal mucosa (a) pH 6.4 PBS (b) isopropyl alcohol, (c) drug solution, (d) optimized pharmacosome F7.

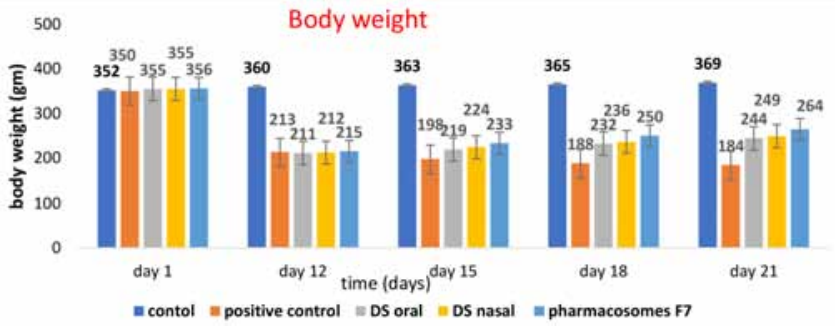

Figure 7: Comparison of body weights of rats administered with optimized formulation F7, DS oral and DS nasal. Mean $\pm S D(n=6)$

\section{PHARMACODYNAMIC STUDY}

\section{Estimation of Behavioral Parameter}

Pharmacodynamic activity by Rotinone induced model

The results of body weight varation, locomotor activity and grip strength on rotarod were plotted as bar graphs and shown in Figure 7-9 respectively. In all behavioral parameters, control group was considered as $100 \%$. Statistical comparisons were made using GraphPad Prism (viewer mode) 8.0.1.

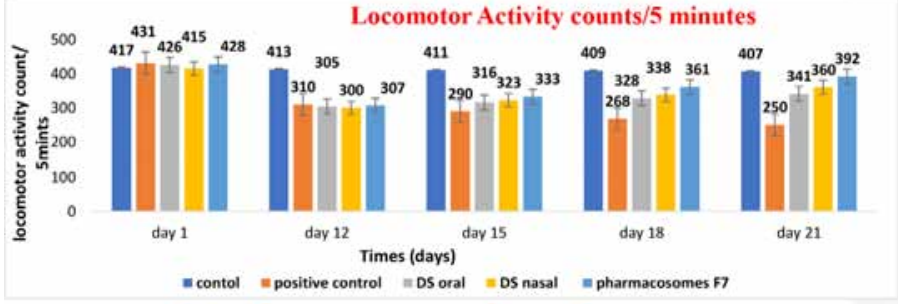

Figure 8: Comparison of locomotor activity of rats administered with optimized formulation F7, DS oral and DS nasal.

Mean \pm SD $(n=6)$

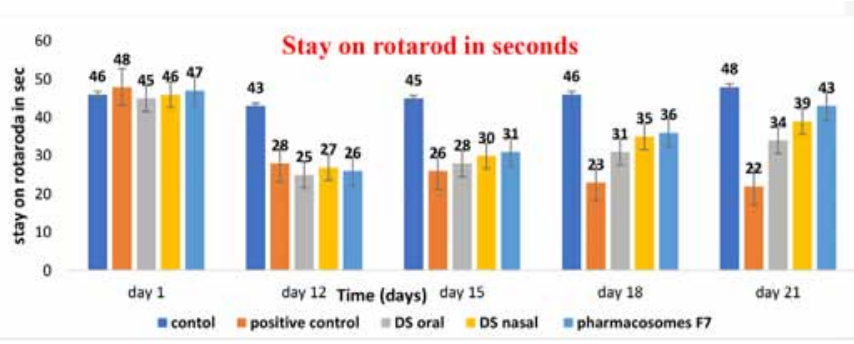

Figure 9: Comparison of grip strength of rats on rotarod administered with optimized formulation F7, DS oral and DS nasal.

Mean \pm SD $(n=6)$

\section{Body weight}

When the treated groups were compared to control, body weight in pharmacosome F7 was restored to $43.2 \%$, DS nasal to $35 \%$ DS oral to $32.4 \%$.

\section{Locomotors activity}

When all the treated groups were compared to control, locomotors activity in pharmacosome F7 was restored to $90 \%$, DS nasal to $70 \%$, DS oral to $57 \%$.

\section{Grip strength of rat on rotarod}

When all the treated groups were compared to control, grip strength on rota rod in pharmacosomes F7 was restored to $65 \%$, DS nasal to $50 \%$, DS oral to $30 \%$.

Histopathology of Mid brain of substantial nigra region of rat brain after exposure to 11 days of treatment

Histopathology of stained sections from mid brain of substantia nigra region of rat brain after exposure to 11 days of treatment with Formulation, drug solution was Figure 10. The positive control group (rotenone induced) showed necrosis of neurons and lesions. The groups treated with DS oral and DS nasal showed mild lesions whereas optimised formulation F7 treated group not showed any lesions which indicates clear recovery from Parkinson's disease.

\section{Biochemical Parameters}

The results of levels of reduced glutathione, nitric oxide, total protein and lipid peroxidation were plotted as bar graphs and shown in Figure 11.

In all biochemical parameters, control group was considered as $100 \%$. Statistical comparisons were made using Graph Pad Prism (viewer mode) 8.0.1. 


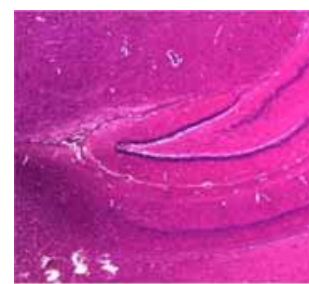

a. Control

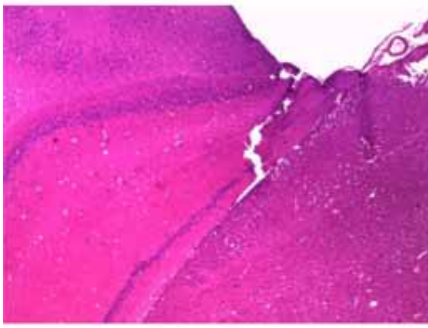

c. DS oral

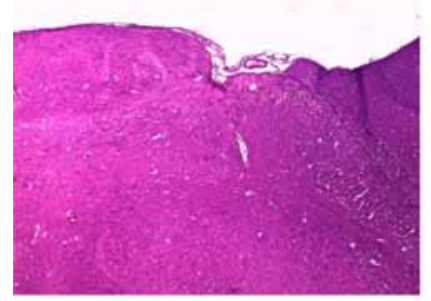

(e) Optimized pharmacosomes F7

Figure 10: Histopathology of Mid brain of substantia nigra region of rat brain after exposure to 11 days of treatment.
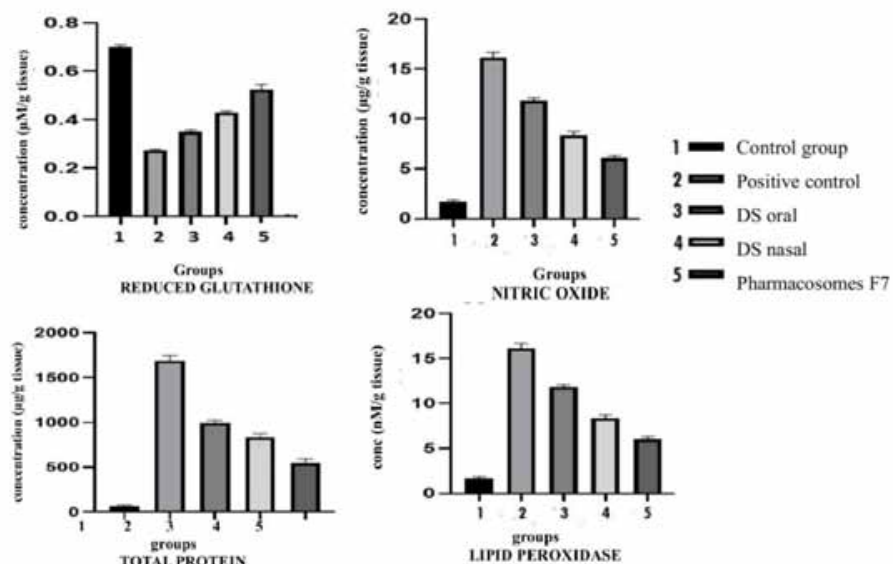

Figure 11: Comparison of levels of reduced glutathione, nitric oxide, total protein and lipid peroxidation.

Mean $\pm S D(n=6)$

\section{Estimation of reduced Glutathione}

When the treated groups were compared to control, the level of reduced glutathione in pharmacosomes F7 was restored to $67.4 \%$, DS nasal to $30 \%$, DS oral to $10 \%$.

\section{Estimation of Nitric Oxide}

When all the treated groups were compared to positive control, the levels of nitric oxide decreased by $82.2 \%$ in pharmacosomes F7 treated group, $54 \%$ in DS nasal and $28 \%$ in oral group

\section{Estimation of total protein}

The total protein in pharmacosomes formulation nasal F7 treated group was significantly decreased by $88 \%$, DS nasal by $74 \%$ and DS oral by $55.8 \%$.

\section{Estimation of lipid peroxidation}

The levels of lipid peroxidation in pharmacosome F7 treated group was significantly decreased by $73 \%$, DS nasal by $63.2 \%$ and DS oral by $33 \%$.

Therefore, we conclude that optimized formulation F7 showed significantly high $(p<0.001)$ pharmacodynamic activity and biochemical parameters when compared to nasal drug solution $(p<0.01)$ and oral drug solution $(p<0.001)$.

\section{CONCLUSION}

In the present study, pharmacosomes of levodopa were developed for delivery via intranasal route and evaluated for the pharmacodynamic activity in comparison to oral route. In ex-vivo permeation studies on porcine nasal mucosa, formulation F7 and F5 showed 3.12 times and 2.26 times enhancement in the steady state flux compared to drug solution respectively. Antiparkinson's activity in rats administered with Optimized pharmacosomes formulation showed significant increase in rat weight, locomotor activity by photoactometer and grip strength on rotarod. Biochemical parameters studied on homogenate of brain further showed significant reduction in levels of lipid peroxidase, nitric oxide, total protein and significant increase in reduced Glutathione $(P<0.001)$ compared to drug solution treated via oral $(P<0.001)$ and drug solution via nasal route $(P<0.01)$. Also nasal drug solution showed significantly high $(P<0.001)$ in pharmacodynamic activity compared to drug solution via oral route. Therefore, we conclude that intranasal pharmacosomes or solution administration could be potential benefit compared to oral route.

\section{ACKNOWLEDGEMENT}

We Acknowledge UCPSc, Kakatiya University, Warangal, Telangana, India, for providing all the facilities to perform the experimental work.

\section{CONFLICT OF INTEREST}

The authors declare no conflicts of interest.

\section{REFERENCES}

1. Giovanna R, Elena S, Massimo C, Elisabetta GPG, Alessandro D. Particulate formulations based on chitosan for nose-to-brain delivery of drugs: A review. JDDST. 2015.

2. Pardeshi $C V$, Veena SB. Direct nose to brain drug delivery via integrated nerve pathways bypassing the blood--brain barrier: An excellent platform for brain targeting. Expert Opin Drug Deliv. 2013.

3. Alazne D, Antonia A, Enrique H, Suarez-Merino B, Goni-de-Cerio F. Central nervous system diseases and the role of the blood-brain barrier in their treatment. Neuroscience Discovery. 2013.

4. Weihai $Y$. The nose may help the brain: Intranasal drug delivery for treating neurological diseases. Future Neurol. 2008;3(1):1-4.

5. Vyas TK, Babbar AK, Sharma RK. Developed intranasal mucoadhesive microemulsions of clonazepam preliminary studies on brain targeting. J Pharm Sci. 2006;95(3):570-80.

6. Illum L. Nasal drug delivery: Possibilities, problems and solutions. Journal of Controlled Release. 2003;87(1-3):187-98.

7. Kublik H, Vidgren MT. Nasal delivery systems and their effect on deposition and absorption. Adv Drug Deliv Rev. 1998;29(1-2):157-77.

8. Chein YW, Su K, SE, Chang SF. Anatomy and physiology of the nose, Nasal systemic drug delivery. Drugs and Pharmaceutical Science, Marcel Dekker, New York. 1989;39:1-19.

9. Chun IK, Lee YH, Lee KE, Gwak HS. Design and evaluation of levodopa methy ester intranasal delivery systems. Journal of Parkinson's Disease. 2011;1(1):101-7.

10. Danielyan L, Schafer R, Ameln-Mayerhofer $V$, et al. Therapeutic efficacy of intranasally delivered mesenchymal stem cells in a rat model of Parkinson disease. 
Rejuvenation Res. 2011;14(1):3-16.

11. Kim TK, Kang W, Chun IK, Oh SY, Lee YH, Gwak HS. Pharmacokinetic evaluation and modeling of formulated levodopa intranasal delivery systems. European Journal of Pharmaceutical Sciences. 2009;38(5):525-32.

12. Merkus FW, Schipper NG, Hermens WA, Romeijn SG, Verhoef JC. Absorption enhancers in nasal drug delivery: Efficacy and safety. J Contaol Rel. 1993;24(1-3): 201-8.

13. Bingham AD, Standish MM, Watkins JG. The action of steroids and streptomysin S on the permeability of phospholipid structures to cations. J Mo Biol. 1965;13(1):238

14. Seem MJ, Pournima M, Manisha K, Vilasro K. Novel vesicular system: An overview. J Appl Pharm Sci. 2012;2(1):193-202.

15. Singh VK, Patel A, Chandra D, Yadav KK. Pharmacosomes: A novel carrier for targeted and controlled vesicular drug delivery system. World J Pharm Sci. 2014;3(5):1221-38

16. Sharma S, Lohan S, Murthy RSR. Formulation and characterization of intranasal mucoadhesive nanoparticulates and thermo-reversible gel of levodopa for brain delivery. Drug Development and Industrial Pharmacy. 2014;40(7):869-78.

17. Srividya R, Krishnaveni J. Brain targeting of chitosan-based diazepam mucoadhesive microemlusion via nasal route: Formulation optimization, characterization, pharmacokinetic and pharmacodynamic evalution. Drug Development and Industrial Pharmacy. 2019;45(1):147-58.

18. Chen L, Subirade M. Chitosan (beta)-lactoglobulin core shell nanoparticles as nutraceutical carriers. Biomaterials. 2005;26(30);6041-53.

19. Raj R, Wairkar S, Sridhar V, Gaud R. Pramipexole dihydrochloride loaded chitosan nanoparticles for nose to brain delivery: Development, Characterization and in vivo anti-Parkinson activity. International Journal of Biological Macromolecules. 2018;109:27-35.

20. Singh RM, Saini PK, Mathur SC, Singh GN, Kumar S. Application of high perfor mance liquid chromatography to the determination and validation of levodopa in methanolic extract of Mucuna utilis. International Journal of Green Pharmacy.
2010;4(3)

21. Krishna SA. Pharmacosomes: A novel carrier for drug delivery. Inn Orig Int J of Sci. 2016;3(6):4-6.

22. Kumar M, Misra A, Babbar AK. Intranasal nanoemul- sion based brain targeting drug delivery system of risperidone. Int J Pharm. 2008;358(1-2):285-291.

23. Zhang $Q$, Jiang $X$, Jiang $W$. Preparation of nimodi- pine-loaded microemulsion for intranasal delivery and evaluation on the targeting efficiency to the brain. Int J Pharm. 2004;275(1-2):85-96.

24. Ramesh G, Chinna RP, Vamshi VY. Enhanced bioavail- ability of lacidipine via microemulsion based transdermal gels: Formulation optimization, ex vivo and in vivo charac- terization. Int J of Pharm. 2010;388(1-2):231-41.

25. Baboota S, Shakeel F, Ahuja A. Design, developmentand evaluation of novel nano emulsion formulations for trans- dermalpotentialofcelecoxib. Acta Pharm. 2007;57(3):315-32.

26. He CX, He ZG, Gao JQ. Microemulsions as drug delivery sys-tems to improve the solubility and the bioavailabilityof poorly water-soluble drugs. Expert Opin Drug Deliv. 2010;7(4):445-60.

27. Kumar M, Misra A, Babbar AK. Intranasal nanoemul- sion based brain targeting drug delivery system of risperidone. Int J Pharm. 2008;358(1-2):285-91.

28. Green LC, Wagner DA, Glogowski J, Skipper PL, Wishnok JS, Tannenbaum SR. Analysis of nitrate, nitrite and $[15 \mathrm{~N}]$ nitrate in biological fluids. Analytical Biochemistry. 1982;126(1):131-8.

29. Lowry OH, Rosebrough NJ, Farr AL, Randall RJ. Protein measurement with the Folin phenol reagent. Journal of Biological Chemistry. 1951;193:265-75.

30. Ohkawa H, Ohishi N, Yagi K. Assay for lipid peroxides in animal tissues by thiobarbituric acid reaction. Analytical Biochemistry. 1979;95(2):351-8.

31. Alam MI, Beg S, Samad A. A Strategy for effective brain drug delivery. Eur J Pharm Sci. 2012;40:385-403.

32. Angeline MS, Chaterjee P, Anand K, Ambasta RK, Kumar P. Rotenone-induced parkinsonism elicits behavioral impairments and differential expression of parkin heat shock proteins and caspases in the rat. Neuroscience. 2012;220:291-301.

Article History: Submission Date : 30-03-2020; Revised Date : 23-04-2020; Acceptance Date : 26-05-2020.

Cite this article: KothaY, Kandhula AG, Janapareddi K. Development and Characterisation of Levodopa Loaded Pharmacosomes for Brain Targeting via Intranasal Route: Pharmacodynamic Evaluation in Rats. JYoung Pharm. 2020;12(2)Suppl:s56-s62. 